Check for updates

Cite this: RSC Adv., 2019, 9, 19560

\title{
Molecular structure characterization of asphaltene in the presence of inhibitors with nanoemulsions $\uparrow$
}

\author{
Mahmoud Alhreez (D) a and Dongsheng Wen*ba
}

Molecular structure characteristics and morphological features of asphaltene can be significantly influenced by the addition of asphaltene inhibitors (AI). We have recently developed a novel concept of using nanoemulsions (NE) as carriers for controlled release of asphaltene inhibitors, which could prohibit the precipitation problem with reduced Al quantity. In this work, X-ray diffraction (XRD) was utilized to investigate the changes in the stacking behaviour of asphaltenes in the presence of three cases: (i) strong organic acids (dodecyl benzene sulfonic acid, DBSA), (ii) nanoemulsions (blank NEs), and (iii) nanoemulsion loaded DBSA (DBSA NEs). Based on the XRD and transmission electron microscopy (TEM) analyses, the stacking distance between aromatic rings of asphaltene was found to be increased by $22.2 \%$, suggesting that the modification of the $\pi$ system over the aromatic zone prevented the ultimate $\pi-\pi$ interactions between asphaltene sheets. The evidence of multiple intermolecular interactions quantitatively obtained from Fourier-transform infrared spectroscopy (FTIR) supported our proposed mechanism for controlled release effect and long-term asphaltene stability, i.e., the decrease of the aromaticity and the reduction in the aliphatic side chains of asphaltene. The refractory nature of asphaltenes was examined by thermogravimetric analysis (TGA), which showed that the asphaltene structure was improved considerably and the coke yield was decreased by $62 \%$ due to the decrease of the cluster size and the increase of the stacking distance.

Received 9th April 2019

Accepted 18th May 2019

DOI: 10.1039/c9ra02664a

rsc.li/rsc-advances fractions also can be determined by XRD. ${ }^{15}$ For example, AlHumaidan et al., ${ }^{16}$ studied the influence of thermal cracking on the molecular structure of asphaltene, and their results showed that the distance between two aromatic sheets $\left(d_{\mathrm{m}}\right)$, distance between the two aliphatic chains or saturated rings $\left(d_{\gamma}\right)$, and the size of the aromatic sheets $\left(L_{\mathrm{a}}\right)$ were not significantly affected by the thermal cracking intensity. The condensed sheets may also contain heteroatoms such as oxygen, sulfur, and nitrogen atoms which could act as free radicals for anchor points of bound metals such as Ni, V, Mo or Fe. Yin et al. ${ }^{17}$ investigated the interaction of $\mathrm{V}$ and $\mathrm{Ni}$ with condensed aromatic compounds. Their results showed that no interactions between metals and aromatic rings of asphaltene have been detected using UV-vis and fluorescence spectroscopy.

Chemical treatments are generally used to alter the macroscopic properties of asphaltenes and improve heavy oil properties by alteration of asphaltene structural characteristics and change of nanoaggregate size. ${ }^{18,19}$ Afraa et al. ${ }^{20}$ used (anacardic acid, cardanol, and cardol (ACC)) as a solvent to investigate its effects on the aggregation behaviour of asphaltene by using XRD. The results revealed the modification of both the aromaticity and the layer distance between two aromatic sheets after the treatment with the solvent. Recently investigators have examined the effects of bio-oils on asphaltene structure. ${ }^{19,21,22}$ They found that bio-oil, extracted from biodegradable substances such as waste cooking oil, and swine waste, does not
${ }^{a}$ School of Chemical and Process Engineering, University of Leeds, Leeds, UK. E-mail: d. wen@leeds.ac.uk

${ }^{b}$ School of Aeronautic Science and Engineering, Beihang University, Beijing, China. E-mail:d.wen@buaa.edu.cn

$\dagger$ Electronic supplementary information (ESI) available. See DOI: $10.1039 / \mathrm{c} 9 \mathrm{ra} 02664 \mathrm{a}$ 
only weaken the clustering of asphaltene but also improve the overall colloidal structure of asphaltene. However, the literature is struggling with how these compounds can affect the properties of asphaltene and what kind of molecular interactions are responsible for their activity. ${ }^{\mathbf{2 3 - 2 5}}$

Even though asphaltene inhibitors are widely used in oilfields as common methods to prevent the aggregation and precipitation of asphaltene, ${ }^{25,26}$ a major problem due to the heavy loss of inhibitors and hence high treatment cost makes asphaltene inhibition by inhibitors uneconomic. We have proposed a novel concept of using nanoemulsion as a carrier for $\mathrm{AI}$ and control its release inside asphaltene solution to increase asphaltene stability. ${ }^{27}$ The findings confirm that NEs could (i), significantly decrease the inhibitors usage (ii) improve the asphaltene stability, and (iii) extend the treatment time via the slow release of AIs with high efficiency. However, a complete molecular analysis of asphaltene and a systematic understanding of how asphaltene molecular structure changes with the addition of inhibitors have not yet been achieved.

In the present work, we attempted to provide novel insights into the stability and molecular modification structure of asphaltene in the presence of three cases: (i) pure DBSA, (ii) blank NEs, and (iii) DBSA NE. Based on the structural parameters obtained from combined XRD, transmission electron microscopy (TEM), and Fourier-transform infrared spectroscopy (FTIR), a stability mechanism was proposed to describe changes in asphaltenes and the effects of DBSA NEs thereon. The thermal stability and the refractory nature of asphaltene are also performed by a thermogravimetric analyser (TGA).

\section{Experiment and methods}

\subsection{Chemicals}

Chemical materials were purchased from Sigma-Aldrich company including solvents such as xylene (>98.5\%), $n$ heptane (extra pure $\geq 98 \%$ ), toluene (extra pure $\geq 98 \%$ ), surfactants such as Tween 80 (sorbitan monooleate), sodium dodecyl sulfonate (SDS) and asphaltene inhibitor dodecylbenzene sulfonic acid (DBSA).

\subsection{Methods and measurements}

2.2.1. Synthesis of nanoemulsions with the presence and absence of inhibitor. The successful long-term stability of AI inside NEs needs different materials than currently used (surfactants) to provide resistant barriers that can prevent quick diffusion of AI from the nanodroplet core. As an example study, DBSA can provide steric and electrostatic repulsion together with hydrophobic and acid-base interactions between its molecules and ionic/non-ionic surfactants. Such a synergistic effect may overcome the hydrogen bond forces of water molecules and enhance the bounded molecules at the interface, resulting in more hydrophobicity of the oil phase. The procedure of synthesis of nanoemulsions with the presence and absence of AI was elaborated in the previous study, ${ }^{27}$ as depicted in the schematic diagram in Fig. S1 in the ESI. $\dagger$ Table 1 shows the composition and concentrations of all three cases used in this work.

2.2.2. The extraction of asphaltene and sample preparation. The extraction of asphaltene was carried out based on ASTM D2007 by adding crude oil to $n$-heptane at a volume ratio of $1: 40$, which is led to asphaltene destabilization and increasing the asphaltene precipitation rate. ${ }^{28}$ The procedure of asphaltene extraction was reported previously. ${ }^{27}$ For preparation asphaltene solution, a $(0.5 \mathrm{w} / \mathrm{v} \%)$ of the asphaltene was dissolved in a mixture of two solvents: toluene/heptane (Heptol) volume ratio of $60: 40$. To observe the effect of DBSA, blank NEs, and DBSA NEs on asphaltene precipitation structure, samples were slowly added to the asphaltene solution under shear action in an (IKA T2S digital/Ultra-Turrax) homogenizer at a rotation speed of $7000 \mathrm{rpm}$ until a complete combination of the NEs into the asphaltene solution. Then the asphaltene solution with and without DBSA, blank NEs, and DBSA NEs were kept for 3 days for totally evaporation at ambient temperature. The dried solid asphaltenes were degassed for $2 \mathrm{~h}$ at $70{ }^{\circ} \mathrm{C}$ in a vacuum oven prior to the analyses.

2.2.3. Molecular structure characterization of asphaltene. $\mathrm{X}$-ray diffraction of the dried samples was obtained with a highpower (12 kW) X-ray diffractometer (D8 XRD) containing a graphite monochromator, rotating copper anode, and a scintillation counter. The diffraction profiles $\left(6^{\circ} \leq 2 \theta \leq 90^{\circ}\right)$ were measured at ambient temperature using $\mathrm{Cu} \mathrm{K} \alpha$ radiation $(\lambda=$ $1.54055 \AA$ ) at $1 \mathrm{deg} \min ^{-1}$ scanning rate and a step size of 0.02 (2), the final procedure of calculating the crystalline parameters are presented in $\mathrm{S} 2(\mathrm{ESI} \dagger)$. The asphaltene particles morphology was inspected using a transmission electron microscope (FEI Titan Themis Cubed 300 TEM).

At spectra range from 500 to $4000 \mathrm{~cm}^{-1}$, a resolution of $1 \mathrm{~cm}^{-1}$, and 64 scans per spectra, the asphaltene samples were collected on a Bruker TENSOR-270 FTIR spectrometer. FTIR spectra were measured by the attenuated total reflectance (ATR) technique using a Bruker ATR A225 sample cell equipped with a diamond crystal of quadrate area of $2 \times 2 \mathrm{~mm}^{2}$ and a spectral range of crystal from 10000 to $10 \mathrm{~cm}^{-1}$. The FTIR spectrometer was controlled using the OPUS software.

Studying the thermal behaviour of asphaltene in the presence of oxygen is necessary to have a better understanding of the thermal stability of asphaltenes. In a general thermogravimetric analysis (TGA) (a Perkin-Elmer analyzer model TGA7HT), a known amount (9-15 mg) of a solid sample was put in an alumina or a platinum pan and placed in a small furnace. The weight of the sample was constantly measured at $10{ }^{\circ} \mathrm{C} \mathrm{min}^{-1}$ heating. For all cases, the temperature interval ranged from ambient temperature up to $800{ }^{\circ} \mathrm{C}$.

\section{Results and discussion}

\subsection{XRD studies of asphaltenes}

3.1.1. Effect of DBSA on asphaltene structure. Fig. 1 shows that when the asphaltene is stabilized by the addition of $4 \mathrm{vol} \%$ DBSA, the crystalline parameters are changed. The distance between two aromatic sheets $d_{\mathrm{m}}$ of asphaltene is $3.26 \AA$, which increases to $3.70 \AA$ for the asphaltene with DBSA. These results 
Table 1 The composition and concentrations of all three cases

\begin{tabular}{llllll}
\hline Sample & DBSA (vol\%) & Xylene (vol\%) & Tween 80 (vol\%) & SDS (vol\%) \\
\hline DBSA & 4.0 & - & - & - & Water (vol\%) \\
Blank NE & - & 7 & 9.9 & 0.1 & - \\
BDSA NE & 1.0 & 7 & 9.9 & 0.1 & 83 \\
\end{tabular}

are compatible with those reported in the literature..$^{29-31}$ Correspondingly, the distance between the two aliphatic chains or saturated rings $d_{\gamma}$ also increased from 4.70 to $5.25 \AA$ A. However, the height stack of the aromatic sheets vertical to the plane $\left(L_{\mathrm{c}}\right)$ is decreased from 13.3 to $10.31 \AA$. The average number of aromatic sheets $\left(M_{\mathrm{e}}\right)$ in asphaltene cluster is $4.65 \AA$ and it decreases to $3.9 \AA$ after the addition of DBSA molecules. The average diameter of the aromatic sheet $L_{\mathrm{a}}$ and the number of aromatic rings in the aromatic sheet $\left(R_{\mathrm{a}}\right)$ are significantly changed with the addition of DBSA from an average of 7.1 $\AA$ and 2.66 for asphaltene to $6.2 \AA$ and 3 for asphaltene with DBSA respectively. This can be attributed to the effectiveness of DBSA to interact with asphaltene molecules via acid-base interaction, which suggests that the asphaltene becomes looser.

3.1.2. Effect of blank NEs on asphaltene structure. The average interlayer distance $d_{\mathrm{m}}$ for asphaltene stacks with blank NEs are not significantly changed gradually from $3.26 \AA$ for the asphaltene sample to $3.42 \AA$. Therefore, despite the fact that observed changes are considerably small, they give a good indication that the distance between two aromatic sheets of asphaltene cluster is slightly affected and loosened by the addition of blank NEs. The distance between the two aliphatic chains or saturated rings was around $5.01 \AA$ for the asphaltene with blank NEs. The average diameter of the aromatic sheet $L_{\mathrm{a}}$ and the cluster diameter $L_{\mathrm{c}}$ for asphaltene have also decreased with the addition of blank NEs and ranges from an average of 7.1 and $13.3 \AA$ to 6.7 and $11.3 \AA$ respectively. However, the insignificant change in the average number of aromatic sheets $M_{\mathrm{e}}$, the average number of aromatic rings in each aromatic sheet $R_{\mathrm{a}}$, and the number of carbons per aromatic structural $C_{\mathrm{Au}}$

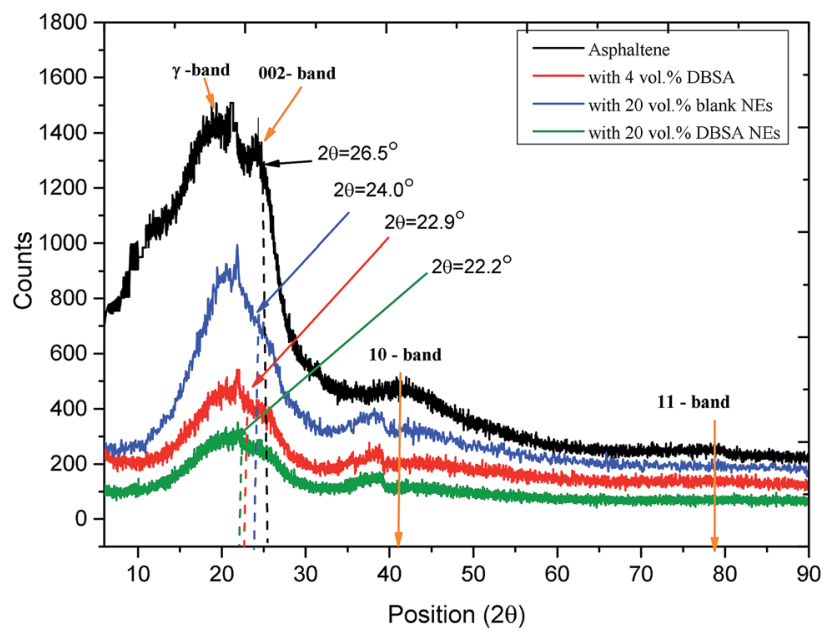

Fig. 1 XRD pattern of asphaltenes with 4 vol\% DBSA, 20 vol\% blank NEs, and 20 vol\% DBSA NEs. compared with asphaltene sample were observed. Thus, these results suggest that blank NEs have a moderate effect on asphaltene structure comparing with using 4 vol\% DBSA. This performance may be owing to the presence of different components in blank NEs such as surfactants, water, and xylene that provide intermolecular interactions with asphaltene molecules.

3.1.3. Effect of DBSA NEs on asphaltene structure. One interesting finding is the distance between the aromatic sheets (stacking space), which is significantly increased from $3.26 \AA$ to $3.96 \AA$ with the addition of DBSA NE to the asphaltene sample. The distance between the two aliphatic chains or saturated rings $d_{\gamma}$ was also affected by the addition of DBSA NE and increased to $5.35 \AA$. In addition, the size of the aromatic sheets $L_{\mathrm{a}}$ has significantly altered with the addition of DBSA NEs from $7.1 \AA$ to $6.1 \AA$. This result is consistent with a reduction of the number of aromatic rings in the aromatic sheet $R_{\mathrm{a}}$ from 3 to 2 . The significant change in the size of the aromatic sheets is primarily due to the fact that, at the addition of DBSA NEs, the aromatic $\mathrm{C}=\mathrm{C}$ bonds are changed. Moreover, the $M_{\mathrm{e}}, R_{\mathrm{a}}$, and $C_{\mathrm{Au}}$ decreased to 3.9, 2.2, and 11.27 respectively. On the other hand, the cluster diameter $L_{\mathrm{c}}$, decreased in size to $10.2 \AA$ as the DBSA NEs is added. The decrease in the cluster diameter of asphaltene is owing to the loss of aliphatic carbon in the alkyl chains and naphthenes that is evidently reflected by the aromaticity $f_{\mathrm{a}}$, which signifies the ratio of aromatic to total carbon per cluster. Because the aromaticity plays a key role in the mechanism of asphaltenes stacking, its modification due to the addition of DBSA NEs should be examined in order to provide more information about the parameters that would change the aromaticity. The determination of aromaticity has a significant advantage to give the aromaticity of aromatic carbon that has the ability to form stacks. It is shown from Table 2 that the aromaticity of the asphaltene sample was 0.35 ; however, after the addition of DBSA NEs this value reduced to 0.22. It is possible that DBSA NEs modify the structure of asphaltene cluster and make it less aromatic. The small value of the aromaticity can be due to either shortening of alkyl side chains or loss of aromatic rings. These findings also suggest that the increasing trend of $d_{\mathrm{m}}$ value for asphaltene with DBSA NEs is consistent with the aromaticity reducing trend. The reduction of aromaticity is indicative of the reduction in the molecular moieties that initiate the stacking and leads to a less ordered structure. It may be supposed that, in this case, the DBSA and other nanoemulsion's components were progressively released from $\mathrm{NE}$ to provide various interactions with asphaltene and involve mainly the breaking of alkyl groups that weakly bond the poly-aromatic basic units, which are saturated the H-bonding sites of asphaltenes and the fact that it 
Table 2 The crystalline parameters obtained from XRD results for asphaltene without and with DBSA, blank NE, and DBSA NE

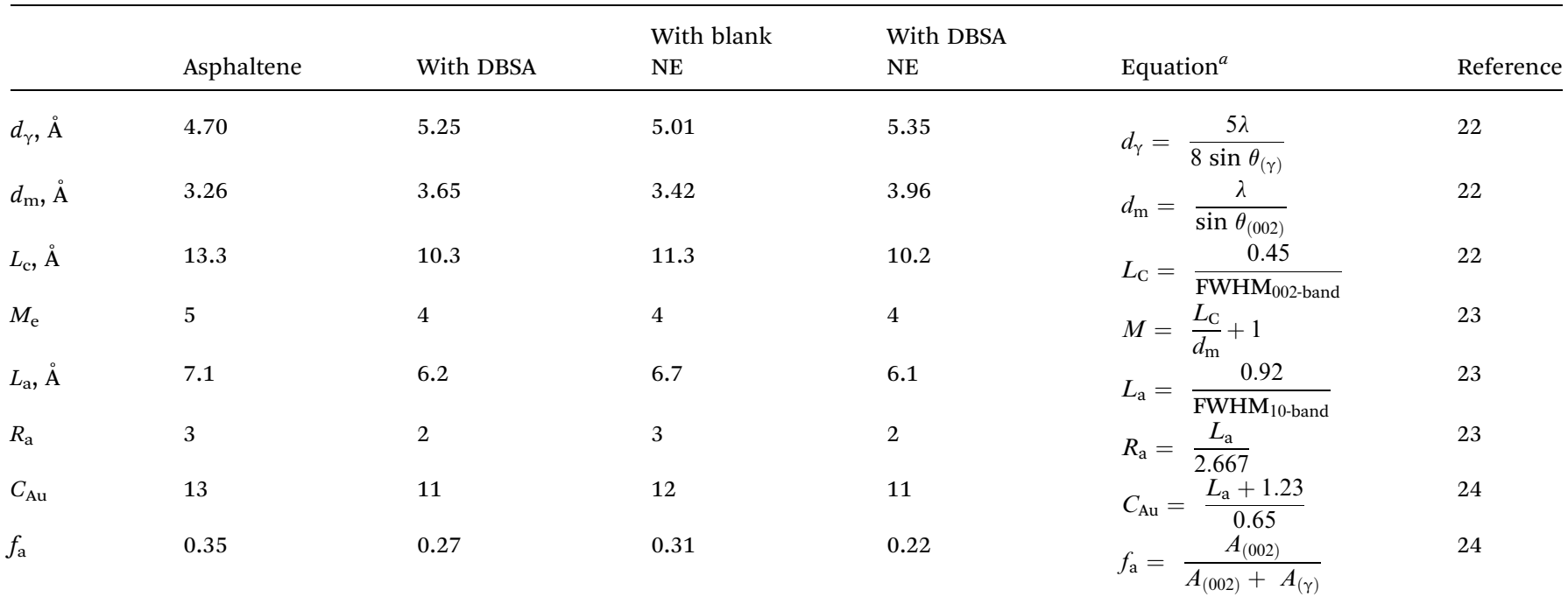

${ }^{a}$ Where $\lambda=1.54055 \AA$ \&; $\theta_{\gamma}, \theta_{002}$, and $\theta_{10}$ are the diffraction angles of $\gamma, 002$, and 10 bands, respectively; FMHM is the full width at half maximum of diffraction peaks, all these values are presented in the Table S1 (ESI). $d_{\gamma}$ : the distance between the two aliphatic chains or saturated rings, $d_{\mathrm{m}}$ : the distance between two aromatic sheets, $L_{\mathrm{a}}$ : the size of the aromatic sheets, $L_{\mathrm{c}}$ : cluster diameter, $M_{\mathrm{e}}$ : the average number of aromatic sheets, $R_{\mathrm{a}}$ : the average number of aromatic rings in each aromatic sheet, $C_{\mathrm{Au}}$ : the number of carbons per aromatic structural. $f_{\mathrm{a}}$ : the aromaticity.

interacted with both the periphery and aromatic cores of asphaltene. This suggests that the asphaltene is prevented from interacting laterally between themselves and kept well-stable in the solution (i.e., increasing asphaltene stability). The significant cleavage in alkyl side chains also produced a decrease in the asphaltene cluster diameter $L_{\mathrm{c}}$ as well as the size of the aromatic sheets $L_{\mathrm{a}}$ and the average number of aromatic rings in each aromatic sheet $R_{\mathrm{a}}$ were affected.

These findings for crystallite parameters of the asphaltene clusters and its aromaticity provide a further comparison between the three cases, which show that asphaltenes with $20 \mathrm{vol} \%$ DBSA NE has an approximately similar result as that of $4 \mathrm{vol} \%$ DBSA. However, the addition of $20 \mathrm{vol} \%$ blank NEs still have some effect but less strong compared with the other two cases. Asphaltene treatment with $20 \mathrm{vol} \%$ DBSA NEs (i.e., containing $0.04 \mathrm{~mL}$ DBSA) give closely the same values of crystallite parameters and aromaticity when treated with 4 vol\% DBSA (i.e., about $0.8 \mathrm{~mL}$ ). Thus, the reduction amount of asphaltene inhibitor $\left(\% R_{\mathrm{AI}}\right)$ is reduced by $95 \%$. The total chemicals usage $\left(\% R_{\mathrm{TC}}\right)$ are again lower than 4 vol\% DBSA by a factor of $10 \%$. These results in very good agreement with the previous work ${ }^{27}$ for reducing AI amount and the total chemicals used, which found that $4 \mathrm{vol} \%$ DBSA and $20 \mathrm{vol} \%$ of DBSA NEs gave the same values of the instability indexes and the sedimentation rates.

We further investigated the effects of DBSA NEs on asphaltene stacking with TEM in order to examine the evidence from the experimental work and support the theoretical predictions. TEM is particularly effective for providing a direct image of nanoaggregates and clusters in asphaltene samples. As shown in Fig. 2A, with the addition of DBSA NEs, the asphaltene cluster size is significantly decreased to about $(5 \mathrm{~nm})$, while the average interlayer spacing between aromatic rings is increased, indicating a gradual stabilization process. Fig. 2B demonstrations the selected area electron diffraction (SAED) images of asphaltene with and without DBSA NEs, which further indicated the transformation of asphaltene sample from unstable to stable by reduction of the $\pi-\pi$ stacking distance between asphaltene molecules. The interlayer distance between the periodic lattice fringes from the (002) plane of asphaltene with DBSA NEs was approximately $0.310 \mathrm{~nm}$. This suggests that DBSA NEs allow significant change about $22.2 \%$ increase in the stacking distance between aromatic rings of asphaltene. These are in very good agreement with the findings obtained from our XRD that indicate the distance between aromatic sheets of asphaltene molecules is reduced in the presence of DBSA NEs.

\subsection{The intermolecular interactions between asphaltene and DBSA NEs}

FTIR is one of the most important analytical techniques, which is used for the determination of functional properties of asphaltene. Despite its versatility, the study of the intermolecular interactions of asphaltene has received little attention by using this technique. ${ }^{32}$ In addition, the literature has been rarely cited about quantitative $\mathrm{e}^{32-34}$ and qualitative ${ }^{35,36}$ analyses for the functional resolution of asphaltenes. The importance of FTIR studies not only to identify the existence and quantity of functional groups but also to provide further information such as the ratio of $\mathrm{CH}_{2}$ to $\mathrm{CH}_{3}$ and the relative amount of aliphatic and aromatic groups, which are essential criteria for crude oil. ${ }^{37}$ Fig. 4 shows the absorption spectrum of extracted asphaltene obtained from FTIR, which showed similar functional groups as reported in other studies. ${ }^{38-40}$ The characteristic peaks of asphaltene molecular structure can be categorized into three types: aromaticity characteristic, aliphaticity characteristic, and polar functionality. ${ }^{39}$ Especially, for the aromaticity characteristic, the adsorption peaks at 750,808 , and $866 \mathrm{~cm}^{-1}$ linked to the out-of-plane $\mathrm{C}-\mathrm{H}$ bending in 1,2-disubstituted aromatic, 1,4-substituted aromatic, and 1,3-disubstituted aromatic, 

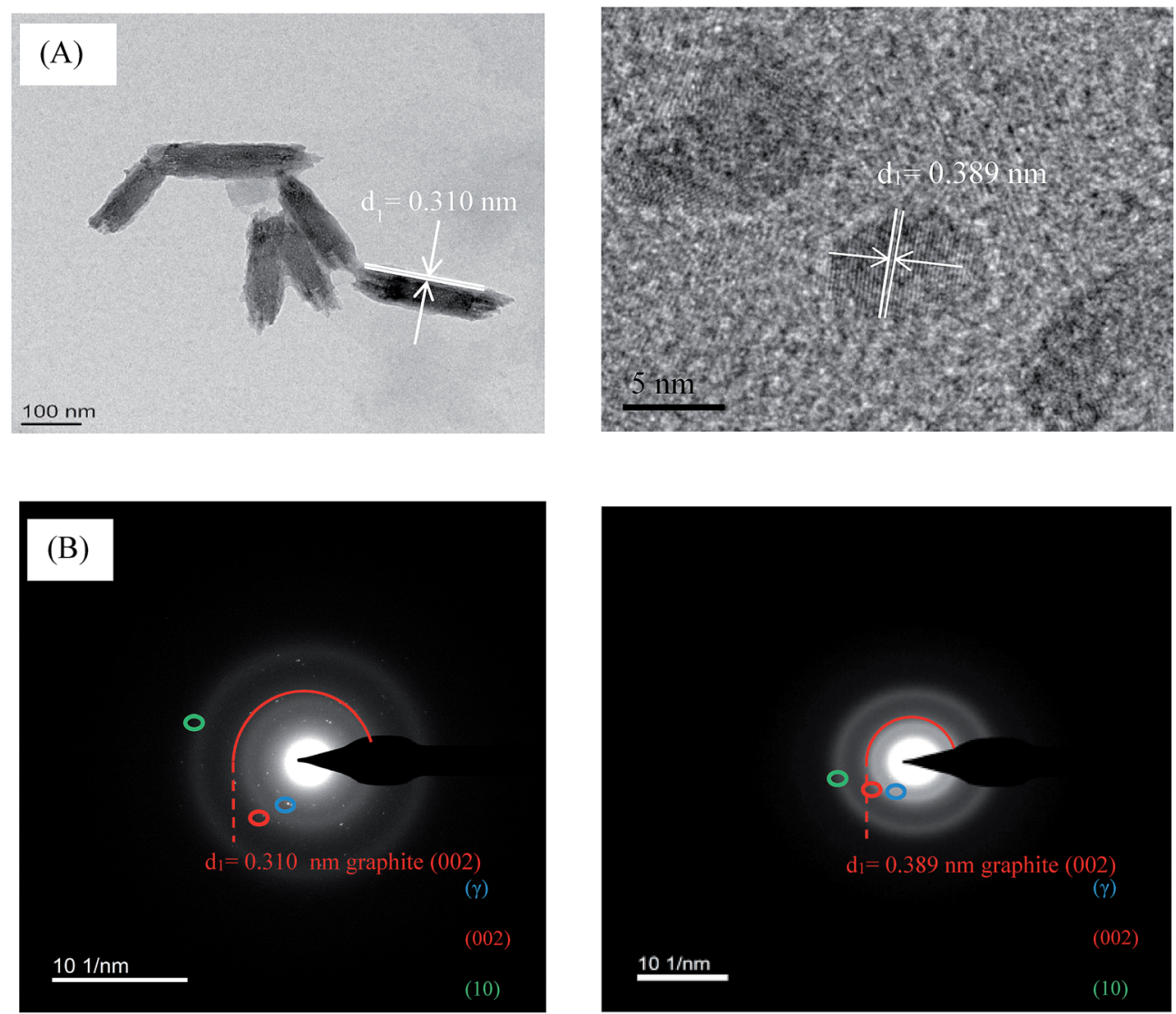

Fig. 2 (A) TEM image of asphaltene, and (B) HRTEM image of asphaltene in the presence of DBSA NEs. The insets are the selected area electron diffraction pattern (SAED), which show the stacking distance measured $d_{002}=0.310$ and $d_{002}=0.389$ for asphaltene without and with the presence of DBSA NEs respectively.

respectively, while the $\mathrm{C}=\mathrm{C}$ stretching vibration in the aromatic structure was allocated at $1602 \mathrm{~cm}^{-1}$. On the other hand, the aliphatic peaks at 2922 and $2852 \mathrm{~cm}^{-1}$ were represented $\mathrm{C}-\mathrm{H}$ stretching vibrations of $\mathrm{CH}_{2}$ and $\mathrm{CH}_{3}$, while the $\mathrm{C}-\mathrm{H}$ bending vibration of $\mathrm{CH}_{2}$ and $\mathrm{CH}_{3}$ peaks were allocated at 1458 and $1375 \mathrm{~cm}^{-1}$. For polar functionality, the absorbance peak at $3458 \mathrm{~cm}^{-1}$ was represented stretching vibrations of $-\mathrm{OH}$ and/or $-\mathrm{NH}$, while the absorbance peak at $1031 \mathrm{~cm}^{-1}$ was signified stretching vibrations of $\mathrm{S}=\mathrm{O}$ in sulfoxides. All functional groups present in are listed in Table S2 (ESI $\dagger$ ).

Looking at Fig. 3, it is apparent that DBSA NEs spectra showed broad strong absorption peak assigned at $3365 \mathrm{~cm}^{-1}$ and this can be attributed to the formation of hydrogen bonds of interlayer water molecules with an anion (DBSA) as well as with hydroxyl groups of non-ion of Tween 80 and SDBS. The colloidal structure of asphaltene can be modified by the addition of DBSA NEs, which provide multiple intermolecular interactions between the asphaltene molecules and the components of DBSA NEs. The ability of DBSA NEs in reducing $\pi-\pi$ stacking and hence increase the stability of asphaltene can be mainly attributed to two mechanisms: acid-base interaction and hydrogen bond interaction. Further investigation for the hydrogen bond of asphaltene and - $\mathrm{OH}$ functional group of DBSA NE molecules was carried out by observing the -OH peak at the wave range of $3150 \mathrm{~cm}^{-1}$ to $3650 \mathrm{~cm}^{-1}$. First, the absorbance of free and hydrogen bonded -OH of different concentrations of DBSA NE at carbon tetrachloride $\left(\mathrm{CCl}_{4}\right)$ was characterized. The hydrogen bonded $-\mathrm{OH}$ band started at $75 \mathrm{vol} \%$ of DBSA NE in $\mathrm{CCl}_{4}$ that is the initial point of the formation of hydrogen bond of DBSA NE molecules. Then this solution (DBSA NE and $\mathrm{CCl}_{4}$ ) was added to asphaltene solution ( $0.5 \mathrm{w} / \mathrm{v} \%$ of asphaltene dissolved with $60 / 40 \mathrm{vol} \% \mathrm{Heptol})$ and FTIR spectrum was collected (Fig. 4).

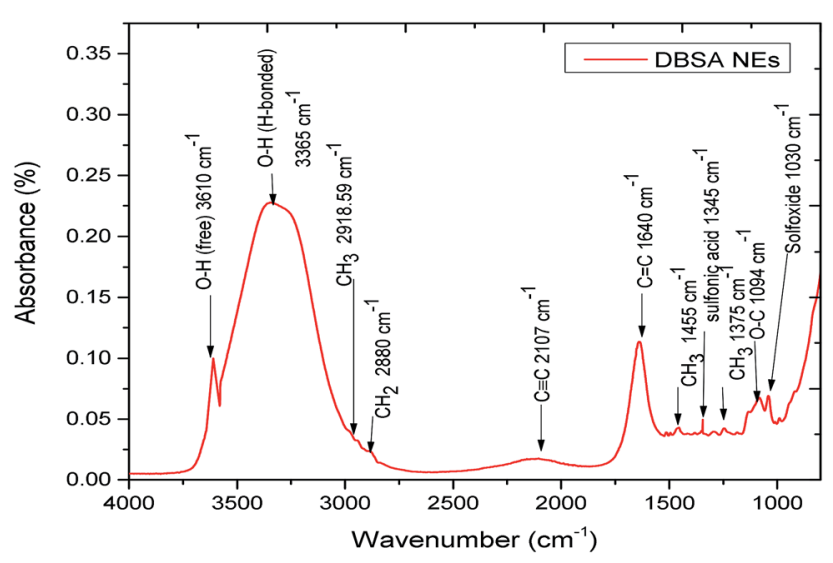

Fig. 3 FTIR of DBSA NEs with 25 vol\% of carbon tetrachloride. 


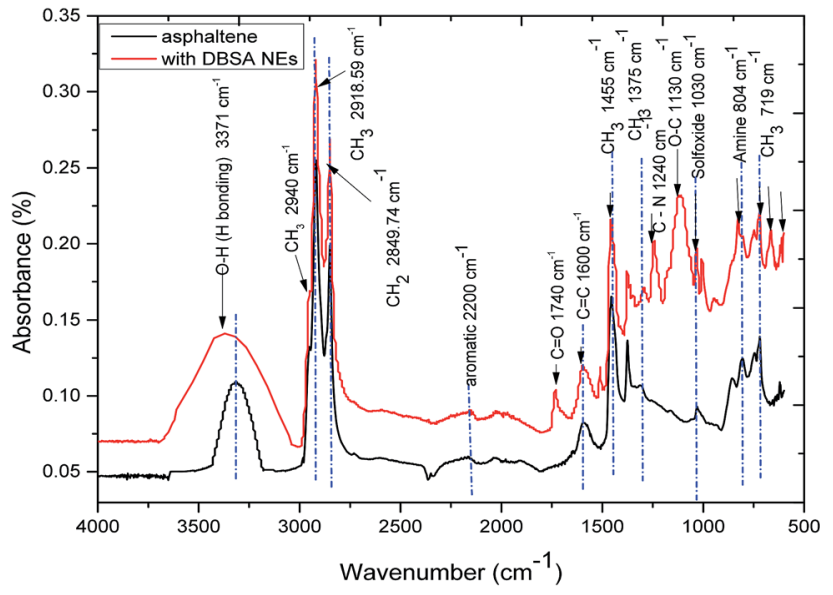

Fig. 4 FTIR of asphaltene with and without DBSA, showing the characteristic bands.

Fig. 4 also presented that, after the addition of asphaltene, the intensity of free $-\mathrm{OH}$ bond at $3606 \mathrm{~cm}^{-1}$ disappeared, while the peak of hydrogen-bonded $-\mathrm{OH}$ at $3365 \mathrm{~cm}^{-1}$ improved. These results indicate that the addition of DBSA NEs to asphaltenes can provide strong hydrogen bonding of free $-\mathrm{OH}$ groups in the DBSA NEs with asphaltene molecules. In addition, the integrated areas under the FTIR spectrums of asphaltene with the presence and absence of DBSA NEs were measured after curve deconvolution and normalizing to quantitatively evaluate any modification. The results show that the integral area of asphaltene with DBSA NEs spectra increases from 2.58 to 5.35 , indicating that asphaltene forms hydrogen bond with DBSA NEs.

Furthermore, the addition of DBSA NEs to asphaltene largely exhibited several additional peaks. For instance, the peak around $1300-1000 \mathrm{~cm}^{-1}$ from the $\mathrm{O}=\mathrm{S}=\mathrm{O}$ stretching vibration shifts of the sulfonic group stretching vibration of asphaltene with DBSA NEs. This should be due to the interactions between the surface heteroatoms of asphaltene and the functional groups of DBSA. Thus, it can be suggested that the release of DBSA molecules can interact with asphaltene and absorb onto the surfaces, via hydrogen bond of $\mathrm{O}=\mathrm{S}=\mathrm{O}$ with $\mathrm{O}-\mathrm{H}$ or $\mathrm{C}-\mathrm{H}$. Besides, the peaks between 660 and $900 \mathrm{~cm}^{-1}$ were higher than for asphaltene without DBSA NEs, which were caused by the intensity vibration of $\mathrm{NH}_{3}$ and $\mathrm{N}-\mathrm{H}$ wagging (shifts on $\mathrm{H}$ bonding). The peak intensity at $1740 \mathrm{~cm}^{-1}$ represented $\mathrm{C}=\mathrm{O}$ (saturated aldehyde) or cis- $\mathrm{RCH}=\mathrm{CHR}$. The changes in out-ofplane $\mathrm{O}-\mathrm{H}$ bonding in the aromatic rings of asphaltene appeared at $675 \mathrm{~cm}^{-1}$, while the peak intensity at $1510 \mathrm{~cm}^{-1}$ caused by $\mathrm{NH}_{2}$ scissoring.

As discussed in the previous study, ${ }^{27}$ this system can overcome asphaltene intramolecular forces, creating new spaces, and involves multiple interactions between asphaltene and DBSA NE components including acid-base interactions, hydrogen bonding, polar $-\pi$ interactions, cation $-\pi$ interactions, and $\pi-\pi$ interactions. These forces can provide additional electrostatic interactions with other ion-pair. For instance, hydrogen bond can be formed between asphaltene and DBSA $\mathrm{NE}$ due to the presence of the hydroxyl group in the chain length with water and surfactants, while acid-base interaction can be appeared due to the presence of the nitrogen in the aromatic core of asphaltene. Thus, the use of a small concentration of DBSA with other components of DBSA NEs is adequate to provide complete coverage of the asphaltene nanoaggregates.

The quantitative comparison of major functional groups in asphaltenes can be investigated by measuring the integrated area of peaks and the intensities of a specific wavelength. To calculate the number of carbon atoms per alkyl side chain, the molar ratio of $\mathrm{CH}_{2} / \mathrm{CH}_{3}$ is required which can be attributed to the ratio of absorbance intensities at wavelengths of 2927 and $2957 \mathrm{~cm}^{-1}$. Also, this ratio can be calculated from the length and the degree of the aliphatic chain by the eqn (1): ${ }^{\mathbf{4 0 - 4 3}}$

$$
N=\frac{n\left(\mathrm{CH}_{2}\right)}{n\left(\mathrm{CH}_{3}\right)}=\frac{A_{2927}}{A_{2957}} \times K
$$

where $K$ is a constant and specified to be 1.243 from correlating of 20 chemicals. ${ }^{40}$ In addition, with the absorbance intensities of 1450 and $1600 \mathrm{~cm}^{-1}$, the molar ratio of aromatic rings to aliphatic side chains can be correlated by eqn (2):

$$
R=\frac{n(\text { aromatic } \mathrm{C}=\mathrm{C})}{n(\text { aliphatic } \mathrm{C}-\mathrm{H})}=\frac{A_{1600}}{A_{1450}}
$$

In addition, in order to know how many aliphatic and aromatic groups in asphaltene, the ratios of the integrated areas $I_{1}\left(2500-3000 \mathrm{~cm}^{-1} / 1600 \mathrm{~cm}^{-1}\right)$ and $I_{2}\left(2500-3000 \mathrm{~cm}^{-1} / 630-\right.$ $930 \mathrm{~cm}^{-1}$ ) should be calculated. ${ }^{\mathbf{4 4}}$

Table 3 shows the values of $N$ and $R$ for asphaltene with and without DBSA NEs samples. It can be seen from these results that asphaltene with DBSA NEs has lower the higher number of carbon atoms per alkyl side chain and it also has lower aromaticity compared with pure asphaltene. It means that the pure asphaltene is the most aromatic sample, while the asphaltene with DBSA NEs is the least aromatic sample. On the other hand, asphaltene with DBSA NEs shows a higher ratio of $\mathrm{I}_{1}$ and $\mathrm{I}_{2}$ than asphaltene without DBSA NEs, indicating the shorter side chain of aliphatic substituents and more amounts of aliphatic and aromatic groups.

The tendency of asphaltene toward the formation of hydrogen bonding can be evaluated by calculating the ratio of the $\mathrm{N}-\mathrm{H}$ and $\mathrm{O}-\mathrm{H}$ intensities $\left(3435 \mathrm{~cm}^{-1}\right)$ over the intensity of aromatic fraction $\left(3100 \mathrm{~cm}^{-1}\right)$. These values in Table 3 imply that the pure asphaltene has the highest propensity toward aggregation by forming hydrogen bonding. The length of alkyl side chain can be attributed to the ratio of the intensities at a wavelength of 1455 and $1376 \mathrm{~cm}^{-1}$. On the other world, the higher ratio means longer side chain. These results are in very good agreement with the aromaticity results obtained from XRD experiments.

Table 3 Asphaltene structure parameters with and without DBSA NEs from FTIR

\begin{tabular}{llllll}
\hline Sample & $N$ & $R$ & $I_{1}$ & $I_{2}$ & $I_{3435} / I_{3100}$ \\
\hline Asphaltene & 2.2 & 0.5 & 1.29 & 0.85 & 0.23 \\
With DBSA NE & 1.8 & 0.42 & 1.52 & 1.05 & 0.188
\end{tabular}




\subsection{Mechanism on the effect of DBSA NEs on asphaltene structure}

According to the experimental results, a possible mechanism was proposed and discussed as followed. The alteration of the asphaltene structure with the addition of DBSA NEs can be attributed to the interactions between the asphaltene molecules and the components of DBSA NEs. Therefore, the ability of DBSA NEs to stabilise asphaltene can be ascribed to several mechanisms such as (i) the slow release of DBSA from NEs can provide the electrophilic addition reaction between DBSA and the $\pi$ electron of asphaltenes by initial breaking its $\mathrm{SO}_{3}-\mathrm{H}$ bond and then bonding its dodecylbenzene sulfonate group with asphaltene molecules. It is worth noting that the DBSA NEs exhibit effective release kinetics due to the use mixtures of anionic and non-ionic surfactants, which can pack closely at the $\mathrm{O} / \mathrm{W}$ interface and thereby make DBSA diffusion from NE slower. Moreover, the slower release rate can be attributed to the small size of DBSA NE (i.e., $21 \mathrm{~nm}$ ), which can provide a high surface area of the system. In fact, higher surface area means a higher surface from which the inhibitor can be released; (ii) the presence of the relatively large lipophilic group (i.e., long-chain alkyl) of DBSA molecules formed adsorbed DBSA like a wedge with a thick tail in the periphery of the new structure. ${ }^{45}$ Similarly, the molecular structures of Tween 80 and SDS can shape themselves similar to lipophilic group of DBSA molecules that can prevent the $\pi-\pi$ interactions between asphaltene molecules by providing steric interferences in those interactions, which therefore prevent asphaltene aggregation. The effectiveness of asphaltenes inhibitors is depended on the length and shape of aliphatic side chains. With increasing in the aliphatic chain length, the inhibitors become able to surround asphaltene molecules strongly; resulting in higher efficiency of the inhibitors; ${ }^{46,47}$ (iii) aromatic compounds of DBSA NEs (i.e., Tween 80, SDS, and xylene) with a certain rigidity of the DBSA head group are able to interact with asphaltene nanoaggregates by $\pi-\pi$ and hydrogen-bond interactions; (iv) $\mathrm{H}_{2} \mathrm{O}$ can also provide an electrophilic addition to the asphaltene's $\pi$-electron by the catalysis of acids (e.g., DBSA) and cause the absorption band in the range of $2000-3000 \mathrm{~cm}^{-1}$ as well as $\mathrm{H}_{2} \mathrm{O}$ molecules can act as a bridge between asphaltene molecules by hydrogen bonding between $\mathrm{H}_{2} \mathrm{O}$ molecules and heteroatoms in asphaltenes. Fig. 5 shows asphaltene molecules with two different nano-colloidal species are achieved after asphaltene molecules stacking. The smaller species is a nanoaggregate of small aggregation number with an aromatic core and an alkane shell. Another species is a cluster with a small aggregation number of nanoaggregates. Whereas the overall length scales for these nano-species are obtained from TEM and $\mathrm{XRD}$ results share many agreements with the Yen-Mullins model. ${ }^{48}$ However, our proposed model involves the molecular structure of asphaltene after the addition of AI or NEs loaded with AI and this must be explicitly accounted for the energetics of aromatic systems, as discussed.

\subsection{Thermogravimetric analysis (TGA)}

The refractory nature of asphaltenes can be confirmed with the wide difference in weight loss, which is relatively insensitive to the temperature. The combustion of pure asphaltenes and asphaltene with DBSA NEs in the presence of air causes weight loss, which has been measured by thermogravimetric analysis and it is presented in Fig. 6A. The presence of air is important to start the oxidation reaction; thus, at a higher temperature, the decomposition rate is very fast. This figure demonstrates that the behaviour of asphaltenes towards coke formation is totally burned off, showing a maximum weight loss at $600{ }^{\circ} \mathrm{C}$. Similar findings were found by Savel'ev et al., ${ }^{49}$ and Maity et al.,${ }^{50}$ using air in the degradation of asphaltene and functionalized asphaltene. However, in the presence of air, about $97 \mathrm{wt} \%$ of another sample (asphaltene with DBSA NEs) is burned at around $600{ }^{\circ} \mathrm{C}$.

The derivative curve clearly shows that two types of asphaltene particles are present due to two main weight losses at $460{ }^{\circ} \mathrm{C}$ and at $585^{\circ} \mathrm{C}$ (Fig. 6B). The first one is named as soft asphaltene and is burned at a lower temperature. While the second one is named as hard asphaltene because it is burned at a higher temperature. These findings are similar to those reported in the literature which suggested the presence of two types of coke in asphaltene sample. ${ }^{\mathbf{5 0 - 5 2}}$ Asphaltene particles are subjected to very severe conditions above $450{ }^{\circ} \mathrm{C}$, leading to form coke as final residue. ${ }^{53}$ Total volatilization is observed at $550{ }^{\circ} \mathrm{C}$; at this temperature and with the presence of oxygen in the air, asphaltene was fully burned and the maximum weight loss is achieved. In addition, at this temperature, intermolecular interactions and weaker chemical bondings were destroyed such as sulfur bridges. However, asphaltene particles are not only changed to coke but also lighter compounds such as gases, oils and resins are expected to be formed. The final residue from asphaltene decomposition was $12.57 \%(2.33 \mathrm{mg})$ of the initial mass, which may consist of typical of polycyclic condensed aromatic hydrocarbon compounds with large aggregates as well as different elements such as $\mathrm{Ni}, \mathrm{Fe}$, and $\mathrm{V}$ that are stable at higher temperatures.

Comparing the thermal profile of asphaltene with the asphaltene with DBSA NEs, the derivative curve clearly develops three consecutive weight loss processes at around $300{ }^{\circ} \mathrm{C}$, $460{ }^{\circ} \mathrm{C}$, and at $585^{\circ} \mathrm{C}$, donating that three types of asphaltene particles are present. TGA curves show that asphaltene with DBSA presented an oscillation peak from 50 to $200{ }^{\circ} \mathrm{C}$, this may be due to the loss of light organic compounds and the residual water (dehydration) obtained from the addition DBSA NEs to the asphaltene. The water molecules directly interact with asphaltene molecules via hydrogen bonding. Hence, it is noteworthy that the loss of water molecules from asphaltene is associated with minor structural changes; however, the framework is kept as the overall shape of the pattern changes little between ambient temperature and $220{ }^{\circ} \mathrm{C}$. The monohydrate phase up to $200{ }^{\circ} \mathrm{C}$ is stable.

After $200{ }^{\circ} \mathrm{C}$ asphaltenes with DBSA NEs suffer continuous decomposition up to around $600{ }^{\circ} \mathrm{C}$. This can be attributed to releasing $\mathrm{CO}, \mathrm{CO}_{2}$ and some hydrocarbons from asphaltene as well as to the loss of long alkyl chains of DBSA NEs components which linked with asphaltene molecules. However, the 2nd peak of the asphaltene sample appeared at $550{ }^{\circ} \mathrm{C}$ and it was 


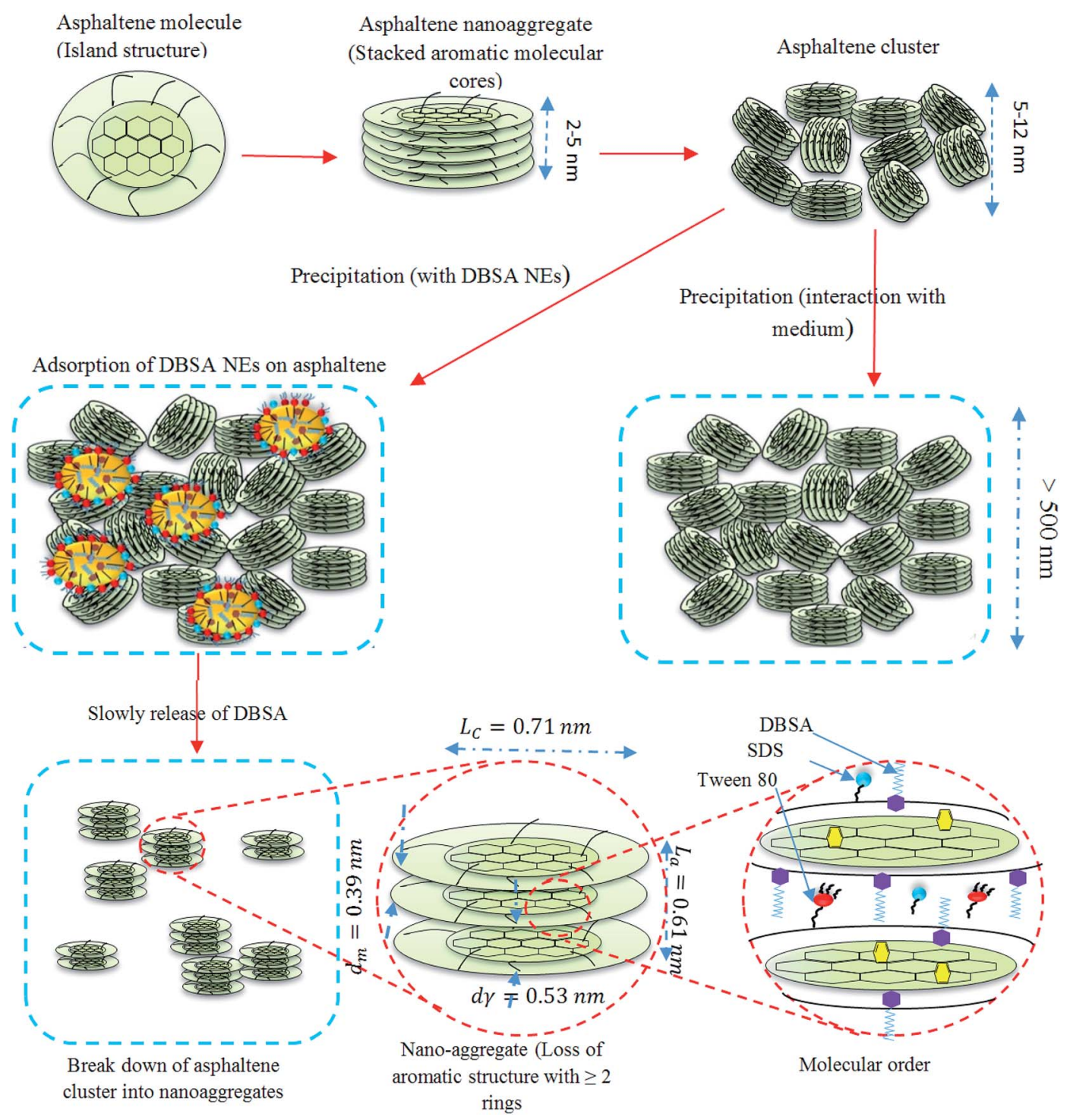

Fig. 5 Schematic representation of the progression of asphaltene molecule and formation of nanoaggregates, with most aging being seen in larger asphaltene clusters (or primary particles). The mechanisms of the adsorption of DBSA NEs on asphaltene and the slow release of DBSA from nanoemulsion affect the stacking distance and the cluster size.

shifted to a higher temperature around $585{ }^{\circ} \mathrm{C}$ for the sample asphaltene with DBSA NEs. The residue at the highest temperature for asphaltene with DBSA is very low about $4.71 \%$, suggesting that formation of multiple intermolecular interactions like hydrogen bond, acid-base interaction, and $\pi-\pi$ interaction between the adjacent molecules of DBSA NEs with asphaltene molecules, which give rise to the high temperature. ${ }^{54}$

The formation of coke from asphaltene decreased when DBSA NEs were added to asphaltene, indicating that DBSA NEs tended to stabilize a proportion of asphaltene. The DBSA NEs can promote the loss of labile points of long alkyl chains in DBSA NEs components which linked with asphaltene molecules, releasing more volatile compounds for example gases. In the initial stages, many of lighter compounds present in asphaltene with DBSA NEs have been volatilized; however, only a few amounts of asphaltene remains during the reaction to finally residue towards coke formation in a small amount compared with pure asphaltene. This can explain why asphaltene with DBSA NEs continuously change in a wide range of temperatures $\left(200-585{ }^{\circ} \mathrm{C}\right)$. This behaviour may indicate that the yield of coke is affected by the presence of DBSA NEs components, reducing it around 62\%. Also, the similarities in the overall shape of the weight loss curves not only confirm that DBSA NEs did not change the main degradation pathways of asphaltene but also indicate that no new materials are formed due to the interaction of DBSA NEs with asphaltene. However, the nature and the structure of hard asphaltene become softer when this is treated with the DBSA NEs as well as the coke yield is decreased. These findings of TGA are in very good agreement with the other results of XRD, TEM, and IFIR for both asphaltenes with and without DBSA NEs presented in this work. 

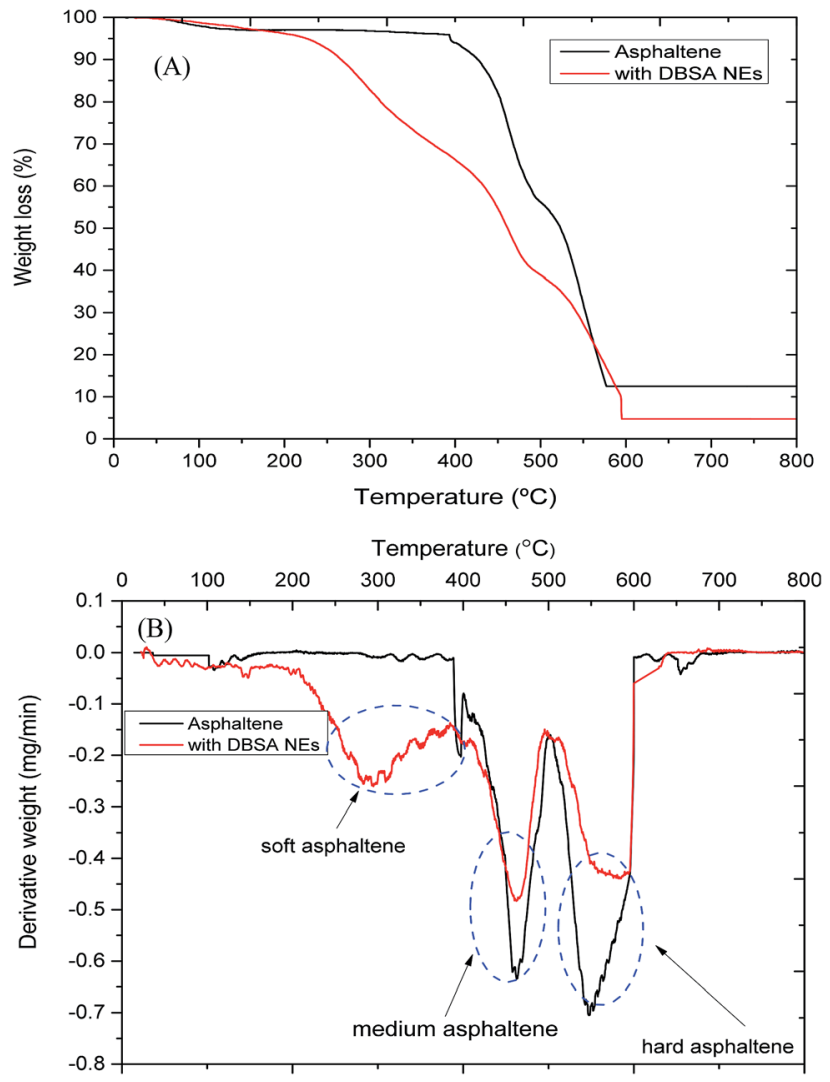

Fig. 6 (A) TGA, and (B) the derivative weight of asphaltene and asphaltene with DBSA NEs in air.

\section{Conclusions}

This work examined the detailed molecular structure of asphaltene in the presence of NEs, and proposed a mechanism of modification structure and stabilizing asphaltene. The experiments by using XRD and TEM confirmed the validity of the mechanism of stabilizing asphaltene by the release of DBSA and other components from NE, which were able to increase both the stacking distance between aromatic rings (about $22.2 \%$ ) and aliphatic chains, and reduce the aromatic sheet diameter and the cluster size. These alterations in molecular structure lead to a decrease of the aromaticity of asphaltene, which in turn increase the solubility of aromatic compounds in the oil and improve the liberation of asphaltene aggregates. In addition, the $\pi$ system over the aromatic zone is changed due to the disruption of the aromaticity that will, in turn, prevent eventual $\pi-\pi$ stacking between asphaltene molecules, which is the main mechanism responsible for the formation of nanoaggregates and clusters.

The FTIR spectroscopic study verified that DBSA NE involves multiple interactions with asphaltene, building up a multicentric electron density in this region, which leads to deeper isosurfaces of van der Waals forces in the interacting zone. In addition, the quantitative study indicated that asphaltenes with DBSA NEs have a lower number of carbon atoms per alkyl side chain, lower aromaticity, shorter side chain of aliphatic substituents, and more amount of aliphatic and aromatic groups compared with pure asphaltene.

The TGA results further demonstrated the alteration of asphaltene structure. It was found that during the chemical reaction between asphaltene and DBSA NEs, the structure of asphaltene is improved considerably and the coke yield is decreased around $62 \%$ due to the decrease of the cluster sizes and the increase of the stacking distance between aromatic sheets.

The findings of this study can contribute to the developments in deep in the enhanced oil recovery process (EOR), finishing processes, and the refining industry in general, as asphaltenes are the heaviest and most problematic hydrocarbon components in crude oil. Revealing the impact of NE to deliver and controlled release of AI on the molecular structure of asphaltene should help our understanding to suggest the best upgrading scheme for heavy crude oils, which is expected to be as a prospective method for preventing oilfield asphaltene.

\section{Conflicts of interest}

There are no conflicts to declare.

\section{Acknowledgements}

This work was supported by European Research Council Consolidator Grant (Grant number 648375).

\section{References}

1 F. B. Silva, M. J. O. C. Guimarães, P. R. Seidl and M. E. F. Garcia, Extraction and Characterization (Compositional and Thermal) of asphaltenes from Brazilian vacuum residues, Brazilian Journal of Petroleum and Gas, 2013, 7(3), 107-118.

2 L. M. da Costa, S. R. Stoyanov, S. Gusarov, X. Tan, M. R. Gray, J. M. Stryker, R. Tykwinski, J. W. de M. Carneiro, P. R. Seidl and A. Kovalenko, Density functional theory investigation of the contributions of $\pi-\pi$ stacking and hydrogenbonding interactions to the aggregation of model asphaltene compounds, Energy Fuels, 2012, 26(5), 27272735.

3 P. C. Painter, M. Sobkowiak and J. Youtcheff, FT-IR study of hydrogen bonding in coal, Fuel, 1987, 66(7), 973-978.

4 M. A. Anisimov, I. K. Yudin, V. Nikitin, G. Nikolaenko, A. Chernoutsan, H. Toulhoat, D. Frot and Y. Briolant, Asphaltene aggregation in hydrocarbon solutions studied by photon correlation spectroscopy, J. Phys. Chem., 1995, 99(23), 9576-9580.

5 S. Acevedo, B. Méndez, A. Rojas, I. Layrisse and H. Rivas, Asphaltenes and resins from the Orinoco basin, Fuel, 1985, 64(12), 1741-1747.

6 B. K. Wilt, W. T. Welch and J. G. Rankin, Determination of asphaltenes in petroleum crude oils by Fourier transform infrared spectroscopy, Energy Fuels, 1998, 12(5), 1008-1012. 
7 R. Zhao and R. Q. Zhang, A new insight into $\pi-\pi$ stacking involving remarkable orbital interactions, Phys. Chem. Chem. Phys., 2016, 18(36), 25452-25457.

8 H. Wang, H. Xu, W. Jia, J. Liu and S. Ren, Revealing the Intermolecular Interactions of Asphaltene Dimers by Quantum Chemical Calculations, Energy Fuels, 2017, 31(3), 2488-2495.

9 J. Ancheyta, F. Trejo and M. S. Rana, Asphaltenes chemical transformation during hydro processing of heavy oils, CRC Press- Taylor \& Francis Group, 2009, p. 441.

10 T. F. Yen, J. G. Erdman and S. S. Pollack, Investigation of the structure of petroleum asphaltenes by X-ray diffraction, Anal. Chem., 1961, 33(11), 1587-1594.

11 J. Christopher, A. S. Sarpal, G. S. Kapur, A. Krishna, B. R. Tyagi, M. C. Jain, S. K. Jain and A. K. Bhatnagar, Chemical structure of bitumen-derived asphaltenes by nuclear magnetic resonance spectroscopy and X-ray diffractometry, Fuel, 1996, 75(8), 999-1008.

$12 \mathrm{~J}$. W. Shirokoff, M. N. Siddiqui and M. F. Ali, Characterization of the structure of Saudi crude asphaltenes by X-ray diffraction, Energy Fuels, 1997, 11(3), 561-565.

13 Y. Bouhadda, D. Bormann, E. Sheu, D. Bendedouch, A. Krallafa and M. Daaou, Characterization of Algerian Hassi-Messaoud asphaltene structure using Raman spectrometry and X-ray diffraction, Fuel, 2007, 86(12-13), 1855-1864.

14 S. I. Andersen, J. O. Jensen and J. G. Speight, X-ray diffraction of subfractions of petroleum asphaltenes, Energy Fuels, 2005, 19(6), 2371-2377.

15 H. M. S. Lababidi, H. M. Sabti and F. S. AlHumaidan, Changes in asphaltenes during thermal cracking of residual oils, Fuel, 2014, 117, 59-67.

16 F. S. AlHumaidan, A. Hauser, M. S. Rana, H. M. Lababidi and M. Behbehani, Changes in asphaltene structure during thermal cracking of residual oils: XRD study, Fuel, 2015, 150, 558-564.

17 C. X. Yin, X. Tan, K. Müllen, J. M. Stryker and M. R. Gray, Associative $\pi-\pi$ Interactions of condensed aromatic compounds with vanadyl or nickel porphyrin complexes are not observed in the organic phase, Energy Fuels, 2008, 22(4), 2465-2469.

18 H. U. Bahia, D. Hanson, M. Zeng, H. Zhai, M. Khatri and R. Anderson, Characterization of modified asphalt binders in superpave mix design, National Academy Press, Washington D.C., 2001, ch. 2, p. 11.

19 M. Mousavi, F. Pahlavan, D. Oldham, T. Abdollahi and E. H. Fini, Alteration of intermolecular interactions between units of asphaltene dimers exposed to an amideenriched modifier, RSC Adv., 2016, 6(58), 53477-53492.

20 S. Afra, H. A. Nasr-El-Din, D. Socci and Z. Cui, Green phenolic amphiphile as a viscosity modifier and asphaltenes dispersant for heavy and extra-heavy oil, Fuel, 2018, 220, 481-489.

21 F. Pahlavan, M. Mousavi, A. M. Hung and E. H. Fini, Characterization of oxidized asphaltenes and the restorative effect of a bio-modifier, Fuel, 2018, 212, 593-604.
22 Y. Lei, H. Wang, X. Chen, X. Yang, Z. You, S. Dong and J. Gao, Shear property, high-temperature rheological performance and low-temperature flexibility of asphalt mastics modified with bio-oil, Constr. Build. Mater., 2018, 174, 30-37.

23 E. H. Fini, S. Hosseinnezhad, D. J. Oldham, E. Chailleux and V. Gaudefroy, Source dependency of rheological and surface characteristics of bio-modified asphalts, Road Mater. Pavement Des., 2017, 18(2), 408-424.

24 A. M. Hung, M. Mousavi, F. Pahlavan and E. H. Fini, Intermolecular interactions of isolated bio-oil compounds and their effect on bitumen interfaces, ACS Sustainable Chem. Eng., 2017, 5(9), 7920-7931.

25 T. Balson, H. A. Craddock, J. Dunlop, H. Frampton, G. Payne, P. Reid and H. J. Oschmann, New methods for the selection of asphaltene inhibitors in the field, Special Publication Royal Society Chemistry, 2002, vol. 280, pp. 254-263.

26 D. Gupta, S. Szymczak, M. Brown, Solid production chemicals added with the frac for scale, paraffin and asphaltene inhibition, SPE Hydraulic Fracturing Technology Conference, Society of Petroleum Engineers, 2009.

27 M. Alhreez and D. Wen, Controlled releases of asphaltene inhibitors by nanoemulsions, Fuel, 2018, 234, 538-548.

28 American Society for Testing and Materials (ASTM), ASTM D6560, Standard Test Method for Determination of Asphaltenes (Heptane Insolubles) in Crude Petroleum and Petroleum Products, 2005.

29 M. M. Boduszynski, Limitations of average structure determination for heavy ends in fossil fuels, Liq. Fuels Technol., 1984, 2(3), 211-232.

$30 \mathrm{~J}$. W. Shirokoff, M. N. Siddiqui and M. F. Ali, Characterization of the structure of Saudi crude asphaltenes by X-ray diffraction, Energy Fuels, 1997, 11(3), 561-565.

31 A. R. S. Nazar and L. Bayandory, Investigation of asphaltene stability in the Iranian crude oils, Iran. J. Chem. Chem. Eng., 2008, 5(1), 3-12.

32 M. D. Guillén, M. J. Iglesias, A. Domínguez and C. G. Blanco, Fourier transform infrared study of coal tar pitches, Fuel, 1995, 74(11), 1595-1598.

33 J. M. Jacobson and M. R. Gray, Use of I.R. spectroscopy and nitrogen titration data in structural group analysis of bitumen, Fuel, 1987, 66(6), 749-752.

34 H. Kallevik, O. M. Kvalheim and J. Sjöblom, Quantitative determination of asphaltenes and resins in solution by means of near-infrared spectroscopy. Correlations to emulsion stability, J. Colloid Interface Sci., 2000, 225(2), 494-504.

35 J. F. McKay, T. E. Cogswell, J. H. Weber and D. R. Latham, Analysis of acids in high-boiling petroleum distillates, Fuel, 1975, 54(1), 50-61.

36 H. A. Akrami, M. F. Yardim, A. Akar and E. Ekinci, FT-IR characterization of pitches derived from Avgamasya asphaltite and Raman-Dinçer heavy crude, Fuel, 1997, 76(14-15), 1389-1394.

37 R. R. Coelho, I. Hovell, M. B. de Mello Monte, A. Middea and A. L. de Souza, Characterisation of aliphatic chains in vacuum residues (VRs) of asphaltenes and resins using 
molecular modelling and FTIR techniques, Fuel Process. Technol., 2006, 87(4), 325-333.

$38 \mathrm{H}$. Wu and M. R. Kessler, Asphaltene: structural characterization, molecular functionalization, and application as a low-cost filler in epoxy composites, $R S C$ $A d v .$, 2015, 5(31), 24264-24273.

39 M. Alhreez, D. Wen and L. Ali, A novel inhibitor for controlling Iraqi asphaltene problems, in International Conference on Environmental Impacts of the Oil and Gas Industries: Kurdistan Region of Iraq as a Case Study (EIOGI), IEEE, 2017, pp. 37-41.

40 M. Mouazen, A. Poulesquen and B. Vergnes, Influence of thermomechanical history on chemical and rheological behavior of bitumen, Energy Fuels, 2011, 25(10), 4614-4621.

41 T. Yan, K. Chen, L. Wang, Y. Liu, Y. Zhang, Z. Jiang and T. Fang, Experimental investigation of upgrading heavy oil with supercritical methanol, Energy Fuels, 2017, 31(6), 5882-5890.

42 D. Zhang, Z. Ren, D. Wang and K. Lu, Upgrading of crude oil in supercritical water: a five-lumped kinetic model, J. Anal. Appl. Pyrolysis, 2017, 123, 56-64.

$43 \mathrm{~J}$. Tong, X. Han, S. Wang and X. Jiang, Evaluation of structural characteristics of Huadian oil shale kerogen using direct techniques (solid-state 13C NMR, XPS, FT-IR, and XRD), Energy Fuels, 2011, 25(9), 4006-4013.

44 V. Calemma, P. Iwanski, M. Nali, et al., Structural Characterization of Asphaltenes of Different Origins, Energy Fuels, 1995, 9(2), 225-230.

45 A. Kabalnov and H. Wennerström, Macroemulsion stability: the oriented wedge theory revisited, Langmuir, 1996, 12(2), 276-292.
$46 \mathrm{~J}$. D. McLean and P. K. Kilpatrick, Comparison of precipitation and extrography in the fractionation of crude oil residua, Energy Fuels, 1997, 11(3), 570-585.

47 J. C. Poveda, D. Molina, H. Martínez, O. Florez and B. Campillo, Molecular Changes in Asphaltenes within H2 Plasma, Energy Fuels, 2014, 28(2), 735-744.

48 O. C. Mullins, The asphaltenes, Annu. Rev. Anal. Chem., 2011, 4, 393-418.

49 V. Savel'Ev, A. Golovko, L. Gorbunova, V. Kamyanov and C. Galvalizi, High-sulfurous Argentinian asphaltites and their thermal liquefaction products, Oil Gas Sci. Technol., 2008, 63(1), 57-67.

50 S. K. Maity, E. Blanco, J. Ancheyta, F. Alonso and H. Fukuyama, Early stage deactivation of heavy crude oil hydroprocessing catalysts, Fuel, 2012, 100, 17-23.

51 S. K. Maity, S. Kumar, M. Srivastava, A. S. Kharola, K. K. Maurya, S. Konathala, A. K. Chatterjee and M. O. Garg, Characterization of asphaltenic material obtained by treating of vacuum residue with different reactive molecules, Fuel, 2015, 149, 8-14.

52 S. K. Sahoo, S. S. Ray and I. D. Singh, Structural characterization of coke on spent hydroprocessing catalysts used for processing of vacuum gas oils, Appl. Catal., A, 2004, 278(1), 83-91.

53 L. H. Velazquez-Jimenez and J. R. Rangel-Mendez, Chemical and thermogravimetric analyses of raw and saturated agave bagasse main fractions with $\mathrm{Cd}$ (II), $\mathrm{Pb}$ (II), and $\mathrm{Zn}$ (II) Ions: adsorption mechanisms, Ind. Eng. Chem. Res., 2014, 53(20), 8332-8338.

54 A. J. Mora, E. E. Avila, G. E. Delgado, A. N. Fitch and M. Brunelli, Temperature effects on the hydrogen-bond patterns in 4-piperidinecarboxylic acid, Acta Crystallogr., Sect. B: Struct. Sci., 2005, 61(1), 96-102. 